\begin{tabular}{|c|l|}
\hline \multicolumn{2}{|l|}{ ALDEIA } \\
\hline $\mathscr{L}$ & NORBERTO DE ALMEIDA DUARTE E ÁLVARO ESCRIVÃO JUNIOR \\
\hline
\end{tabular}

\title{
SAÚDE TRANSNACIONAL
}

Pesquisa da EAESP mostra que os estrangeiros que vivem nos Estados Unidos continuam utilizando serviços de saúde em seus países de origem. A oferta desses serviços em Governador Valadares, no Brasil, possui estreita relação com a demanda do emigrante

As discussões que levaram à recente reforma do sistema de saúde norte-americano, sancionada em março de 2010 pelo presidente Barack Obama, reacenderam o debate sobre a falta de acesso a serviços de saúde por parte de 50 milhões de pessoas que não possuem condições de pagar pelos seguros de saúde privados nos EUA.

Quando se observa que 40\% desse total, ou seja, cerca de 20 milhões de pessoas, são indivíduos estrangeiros, compreende-se por que a questão alcançou um grande espaço nos debates políticos internos e na mídia daquele país. O problema ganha contornos dramáticos com a constatação de que, desses 20 milhões de estrangeiros, cerca de 12 milhões vivem de forma irregular nos EUA. Esses imigrantes ilegais deparam-se com um sistema fragmentado, confuso e hostil. Seus empregadores não oferecem seguro de saúde, e os imigrantes não contam com recursos suficientes para pagar os prêmios desses seguros ou os cuidados médicos diretamente, além de enfrentarem grandes barreiras culturais. 


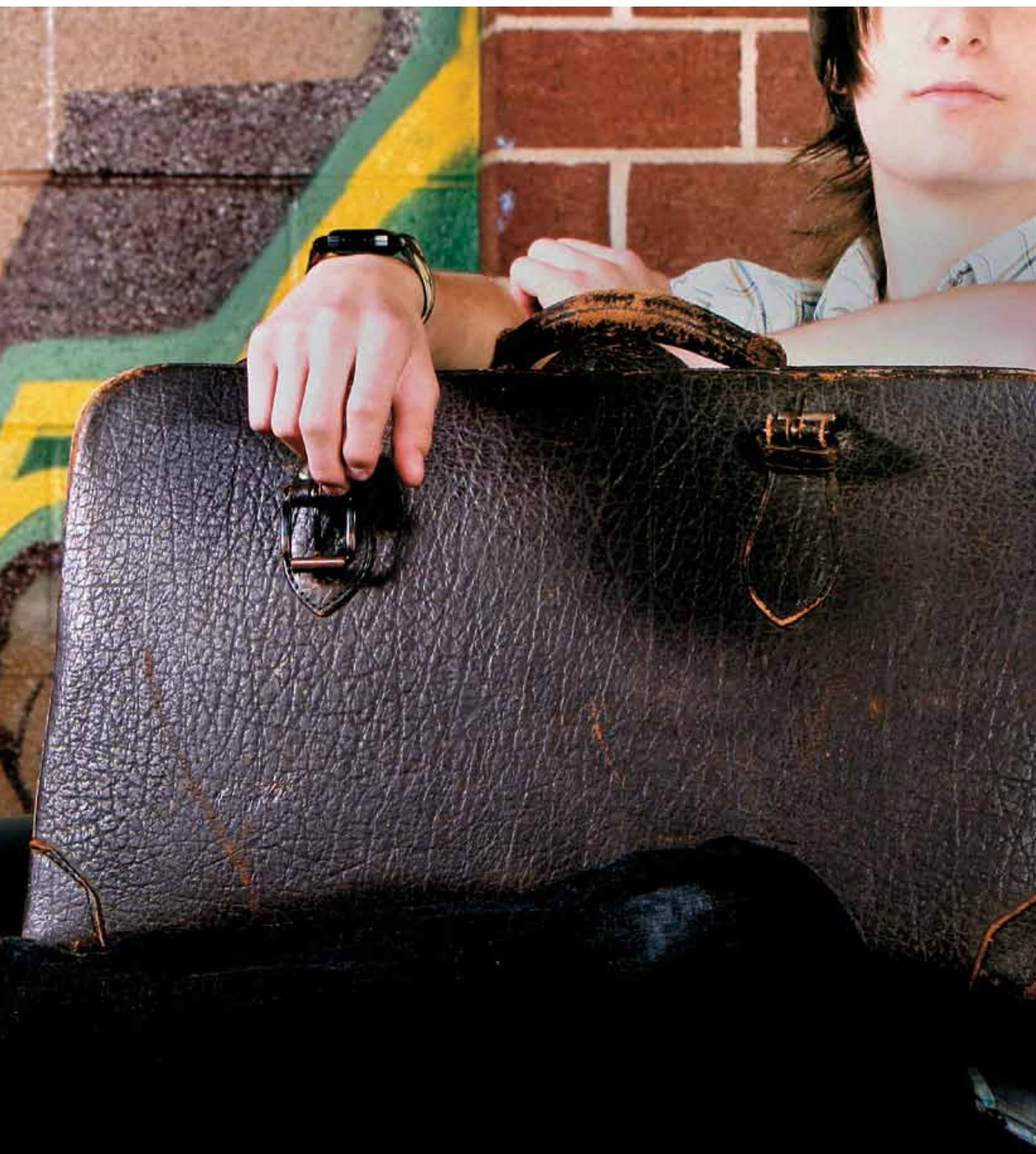


Uma realidade pouco estudada, porém, é o fato de grande quantidade desses indivíduos lidarem com essas restrições ao usarem serviços de saúde nos seus países de origem. Uma pesquisa concluída em 2010 na FGV-EAESP ilustrou de que forma isso ocorre no caso dos brasileiros residentes nos Estados Unidos que têm origem na cidade mineira de Governador Valadares. A pesquisa mapeou as formas como essa comunidade tem acesso a serviços de saúde, e concluiu que o sistema de saúde valadarense atende a uma parte significativa das necessidades dessa população que não reside mais na cidade.

\section{O estado de Massachussets instaurou em 2006 uma reforma na área da saúde que privilegia o acesso ao atendimento médico a imigrantes e a pessoas de menor renda}

BOSTON, MG. Desde a década de 1960, mineiros de Governador Valadares passaram a compor uma importante comunidade de imigrantes brasileiros nos Estados Unidos. Dos valadarenses hoje residentes naquele país, cerca de metade adotou como local de moradia e trabalho a região metropolitana de Boston, em Massachusetts, estado que se distingue por ser mais receptivo à imigração do que as demais unidades da federação norte-americana. $\mathrm{O}$ estado é também berço político do senador Ted Kennedy, falecido em 2009, que foi um dos principais articuladores de uma reforma introduzida em 2006, o Massachusetts Health Reform Act (MHRA), que aumentou a cobertura de serviços de saúde aos residentes do estado.
Para reformar o acesso à saúde no estado, esse ato se orientou por dois princípios: de um lado, todos aqueles que possuem renda compatível com o pagamento de seguros privados passaram a ser obrigados a comprá-los, sob pena de pagar mais imposto de renda; de outro, o estado de Massachusetts arca de maneira integral ou parcial com as despesas médicas dos residentes que não possuem renda compatível com o pagamento desses seguros.

Entrevistas com emigrantes valadarenses mostraram que, por mais que a legislação norte-americana historicamente restrinja o acesso aos cuidados de saúde para uma boa parte da população, as políticas públicas de Massachusetts têm favorecido de forma muito significativa a cobertura das necessidades em saúde de toda a população, inclusive a dos imigrantes. Essa cobertura abrange desde os cuidados de urgência até os ambulatoriais, e a capacidade de infiltração de cada indivíduo nas redes sociais das comunidades de imigrantes parece ser um importante componente facilitador do acesso.

NEM TUDO SÃO FLORES. Por outro lado, é importante compreender que essa realidade encontrada em Massachusetts não se estende a muitas outras partes do território americano. Por um lado, alguns estados, como Illinois, Nova York, o Distrito de Colúmbia, e certos municípios da Califórnia, utilizam fundos próprios para expandir a cobertura do seguro saúde, mesmo para imigrantes ilegais. Em contrapartida, estados como Arizona, Colorado, Geórgia e Virgínia têm aprovado leis que tornam o acesso aos serviços de saúde particularmente difícil para os que não são cidadãos americanos ou residentes legais no país.

Além disso, mesmo em Massachusetts, a derrota democrata para a vaga no senado deixada por Ted Kennedy, 
no início de 2010, pode ser vista como um recado enviado ao governo do presidente Barack Obama pela população desse estado, formada em boa parte por indivíduos com privilegiadas condições socioeconômicas e culturais. Afinal, eles já vêm pagando desde 2006 por um acesso "universal" à saúde para a população ali residente, e as reformas governamentais resultarão em mais tributos. Isso traduz o tamanho da dificuldade de se encontrar uma alternativa que garanta, em maior escala e com abrangência nacional, o acesso aos serviços de saúde para os 50 milhões de indivíduos sem seguros privados naquele país.

\section{Seja pelas restrições americanas ou pela cultura, os mineiros de Governador Valadares aproveitam a visita ao Brasil para irem a médicos e dentistas}

SAÚDE TRANSNACIONAL. Outro importante achado da pesquisa é que, seja pelas restrições governamentais ao acesso aos serviços de saúde norte-americanos - sobretudo nas regiões em que elas são mais acentuadas, como visto acima -, seja pelo custo da assistência em saúde naquele país, ou até mesmo por fatores culturais, o emigrante de Governador Valadares acaba buscando os profissionais e os serviços de saúde da sua cidade, quando retorna a passeio ou para visitar familiares. Uma demanda particularmente frequente é pelos serviços odontológicos, seguidos de perto pelos check-ups ginecológicos, cardiológicos e oftalmológicos.
Foi detectada também, embora com menor intensidade, significativa demanda por serviços de medicina estética e por uma segunda opinião acerca de diagnósticos realizados por profissionais norte-americanos. A pesquisa conclui que o perfil da oferta de serviços de saúde da rede ambulatorial de Valadares acaba por possuir uma estreita relação com a demanda do emigrante.

Essa utilização transnacional e complementar de serviços de saúde por emigrantes de Governador Valadares, nos EUA e na sua cidade de origem, é sem dúvida um exemplo de como os fenômenos migratórios laborais romperam não somente fronteiras geográficas, mas também institucionais. Sua existência, assim como as necessidades dos indivíduos componentes dessas redes sociais, deve ser levada em conta na condução de políticas de acesso à saúde, tanto nos Estados Unidos como no Brasil. Legalizados ou não, esses indivíduos trabalham, frequentam escolas, igrejas, casam, geram filhos e, naturalmente, necessitarão de assistência à saúde no país de destino. Ignorar a questão não resolverá o problema.

O governo Barack Obama até o momento tem tido a coragem de começar a enfrentar problemas dessa ordem, e parece ter consciência de que as questões trazidas por fenômenos como a imigração exigirão novas formas na condução das políticas sociais. Resta ver se Obama terá respaldo político suficiente para avançar em direção a uma solução definitiva.

NORBERTO DE ALMEIDA DUARTE, mestre em Administração de Empresas pela FGV-EAESP, norbert@uai.com

ÁLVARO ESCRIVÃO JUNIOR, professor da FGV-EAESP, alvaro.escrivao@fgv.br 